\title{
Fuzzy Logic Based Online Electromagnetic Loss Minimization of Permanent Magnet Synchronous Motor Drives
}

\author{
Eleftheria S. Sergaki ${ }^{1}$, Pavlos S. Georgilakis ${ }^{3}$ \\ Antonios G. Kladas ${ }^{2}$, and George S. Stavrakakis ${ }^{1}$ \\ ${ }^{1}$ Department of Electronic \& Computer Engineering, Technical University of Crete, Greece, e-mail: elefsergaki@gmail.com \\ ${ }^{2}$ School of Electrical \& Computer Engineering, National Technical University of Athens, Greece \\ ${ }^{3}$ Department of Production Engineering \& Management, Technical University of Crete, Greece
}

\begin{abstract}
The objective of this paper is to give an insight about the development of a fuzzy logic efficiency control system which is incorporated to a standard adjustable speed drive control (i.e. Indirect Vector Control) in order to improve the online efficiency in Permanent Magnet Synchronous Motor (PMSM) drives for both transient and steady state operation. The search criterion in steady state is the minimization of the drive power losses by reducing the stator flux while meeting the speed and load torque demands. The power losses are calculated as the difference between the measured input DC-link power and drive's output power. The power losses are calculated at every sampling step and the change of power losses are calculated over a constant time interval as it is needed by the efficiency control algorithm. Variables in the operating characteristics of the PMSM, such as DC input voltage/current and actual speed are inputs to the fuzzy control system, making the control system independent of any specific load. Our system combines two fuzzy logic designed efficiency controllers which are introduced as Fuzzy(1) and Fuzzy(2) controllers in order to generate the magnetizing current (d-axis component of the stator current). They are separately activated during the steady and transient state respectively. The Fuzzy(1) controller is a search controller (SC) operating in steady state, so to decrease the stator flux for higher efficiency. The $F u z z y$ (2) controller is a $S C$ operating in transient state, so to increase at minimum the magnetizing current, to achieve fast tracking capability, less steady state error and robust to load disturbance during transient state. The torque component of the stator current is generated by the vector controller in order to achieve higher motor performance. The fuzzy logic controllers (FLCs) prototypes were created and tested using Simulink ( simulations. Simulations are accomplished in Simulink (B) in order to validate our method (i.e. efficiency improvement, less torque ripple with flux changes and the less speed sensitivity to load disturbances). Experimental results will be available upon conclusion of the laboratory testings. Future experimental deployments will include a DSP board which will be directly programmed in assembler language via Simulink $®$.
\end{abstract}

\section{INTRODUCTION}

"Direct-Drive" AC motors expand the future of industrial drives. The elimination of the gearbox reduces the parts subjected to maintenance and overall noise, while permits low speeds that potentially increase the operational life. The result is far greater reliability than can be achieved with a conventional geared induction motor. "Direct-Drive" motors are PMSM with a high number of poles. "Rare earth" (NdFeB) permanent magnets have high magnetic energy density, achieving higher efficiency. The PM motor family incorporates two designs: internal rotor and external rotor. Both designs are industrially rated and adopted in critical applications such as elevator winches and wind power generators. The PM motors can be used in Vector Control (VC) or so called Field Oriented Control applications [1]. In VC method the state variables are transformed to a coordinate system synchronously rotating with the rotor. In rotor frame coordinates the PMSM behaves like a separately exited DC motor. The exact value of the rotor position is mandatory: to control the speed; to transform the state variables; to achieve a high efficiency. The VC method is the de facto standard for quickly changing loads as well as for reference speeds. The VC achieves the best dynamic behavior, but requires shorter control cycle times for good lead and disturbance behavior, and does not optimize the overall drive efficiency. Several efficiency optimization control methods have been introduced to cooperate with $\mathrm{VC}$ method for the PMSM drives. The literature [2]-[6] describes different strategies. The [4]-[6] are dealing with loss minimization and high-performance speed (torque) control of PMSM, which are based upon nonlinear control schemes based on feedback linearization and decoupling methods using motor models in which the core loss is represented with core-loss resistances. [4] presents a method for both copper and iron loss minimization of an interior PM motor based on flux-weakening control. However, the proposed condition is complex and cannot be easily implemented. Another control method for efficiency improvement of PMSM, by keeping power factor equal to unity, is described in [7]. However, although the real to apparent power ratio ( $\mathrm{kW} / \mathrm{kVA})$ of the PMSM motor is maximized, power losses are not minimized. In [1] a maximum torque-per-ampere current control is accomplished by online controlling the flux stator component $i_{d s}$ while keeping $i_{d s}$ equal to zero $\left(i_{d s}=0\right)$. In surface PM motor drives, copper loss is minimized.

An efficiency optimization control method that uses online power searching algorithms to adjust one of the drive variables (e.g. magnetizing current, stator voltage) is materialized with 
controllers which are called Search Controllers (SCs) [8]. The $S C$ s control principle is the minimization or maximization of a significant parameter by trial and error. The criterion could be the minimization of the: DC link power or DC link current or stator current or drive losses, etc, [10]. The $S C$ s in [11]-[13] minimize the drive input power by iterative adjustments of the flux level in relation to the load torque and to the rotor speed. The SCs only yield suboptimal operation since parameter variations due to temperature changes and saturation effects are not taken into consideration [14], [15]. The no need for precise knowledge of the motor loss function parameters is the main advantage of the SCs. The problem of slow convergence toward optimum efficiency point, is the main drawback of the $S C$ s. The experimental convergence time of the $S C$ s is no less than $4 \mathrm{~s}$. The torque pulsations around the optimum operating point is a problem for the $S C$ s and may lead to a large drift and instability. Back in 1995, G. D. D. Sousa, B. K. Bose, J. G. Cleland [10] proposed fuzzy efficiency $S C$ for steady states. In 1996-97 and 2006, J.Moreno, M.Cipolla, J.Peracaula, [22]-[23] and E.Sergaki, G.Stavrakakis [9] respectively, introduced efficiency optimization during transient states using fuzzy $S C$ s.

In the present work, the proposed fuzzy efficiency control system is inspired by [9], [10], [22], [23] and improves the drive efficiency of a PMSM with inset magnets and weakening capabilities, during transient and steady state performances. The optimization criterion is the online minimization of the drive losses instead of the motor power losses. It is known that the flux stator component current $i_{d s}$ the one that provides maximum torque-per-ampere current ratio in interior PMSM drives, is a function of the stator torque component current $i_{q s}$ and opposes the excitation field of the PMSM, [11], [16]-[18]. Thus, the PMSM's reluctance torque is produced by controlling the flux stator component current $i_{\mathrm{ds}}$, according to various load and speed conditions.

The outline of our method is explained as follows: The drive power losses are sampled and calculated by a calculating means. The drive power losses value is then compared with a previous value by a comparing means. A change in DC link current value is determined from this comparison, since the DC voltage is essentially constant, by a determining means. A stator flux decrement value is calculated by a calculating means. The stator flux decrement value is based on the change in DC link current value. A stator current value is generated by a generating means. The stator current value is based on the stator flux decrement value. Finally, the stator flux is reduced by a reduction means, based on the stator current value. The flux component of the stator current, $\mathrm{i}_{\mathrm{ds}}$, is generated by the fuzzy $S C$ s based on the stator flux decrement value. The torque component of the stator current, $\mathrm{i}_{\mathrm{qs}}$, is generated by the vector controller based on the $\mathrm{i}_{\mathrm{ds}}$ value, in order to keep the developed electromagnetic torque $T_{e}$ constant. A decrease in stator flux results in a decrease of $\mathrm{i}^{*}{ }_{\mathrm{ds}}$ and a subsequent increase of $i^{*}$, in a way to keep the $T_{e}$ constant. The iron loss in the drive system decreases with a subsequent increase of copper loss, in order for the total system loss to be reduced.

\section{POWER LosS MODELING}

The drive loss minimization criterion includes motor and the converter losses. The influence of the converter losses does not improve the drive's efficiency, but it guaranties higher optimum flux level than this from the motor loss minimization criterion. That improves the drive's robustness. The PMSM drive's total power losses are calculated as the difference between input and output drive power:

$P_{\text {total }}=P_{\text {in }}-P_{\text {out }}=V_{D C} I_{D C}-\omega_{r} T_{e}$,

where: $P_{i n}, P_{\text {out }}$ are the drive input, output power respectively, $V_{D C}$ and $I_{D C}$ are voltage and current in the DC link, $\omega_{r}$ is the motor speed and $T_{e}$ is the electromagnetic torque. The voltage $V_{D C}$ and current $I_{D C}$ can be directly measured, over a samples of consequent time intervals. $T_{e}$ is a known variable in a drive and speed $\omega_{\mathrm{r}}$ can be measured or estimated. So, we are able to calculate the total drive power losses without the need of knowledge of the motor's parameters and independently of the parameter's changes (i.e. due saturation and heating). The minimization of $\mathbf{P}_{\text {total }}$ translates into the minimization of $\mathbf{P}_{\text {in }}$, which is the minimization of the DC link current $I_{D C}$, since the DC link voltage $V_{D C}$ is virtually constant. The change of $P_{\text {total }}$, $\Delta \mathbf{P}_{\text {total }}$ represents at each instance the difference between the current and a previous value over a constant time interval. A negative value of $\Delta \mathrm{P}_{\text {total }}$ indicates a power input efficiency improvement. The Power Loss Processing Unit is incorporated into the proposed fuzzy efficiency system in order to calculate the drive's power losses, during steady states, by (1).

\section{FUZZY LOGIC CONTROLLERS IMPLEMENTATION}

The main advantages of the fuzzy logic control is the fast convergence by using an adaptive step size of the control variable and that it can infuse inaccurate signals (corrupted by noise) without introducing operational instability. The proposed fuzzy logic controllers are of PI type. The actual value of the controlled variable for the PI type fuzzy controller is obtained by the equation:

Variable $($ new $)=$ Variable $($ old $)+\Delta($ new $)$

where $\Delta$ is an adaptive size step for the control variable. The change of the output control variable $\Delta$ is computed according to the measured change of the fuzzy state variable and the sign and magnitude of the last change in $\Delta$, which is labeled $\mathrm{L} \Delta$.

The proposed efficiency fuzzy control system includes two fuzzy efficiency-optimization controllers, the Fuzzy(1) and the Fuzzy(2). They are activated separately, for both steady and transient states respectively. The $F u z z y(1)$ controller is activated during steady state. Three main tasks are accomplished by the Fuzzy(1) controller: (i) Determination of the steady state (when the speed error maintains a particular value for a predetermined period of time and there is no change in torque or when does not exceed a predetermined threshold level); (ii) Direction test (decrement or increment); (iii) Loss minimization. The control block diagrams and the membership functions for the Fuzzy(1), (2) are shown in Fig.1, 2, respectively. 


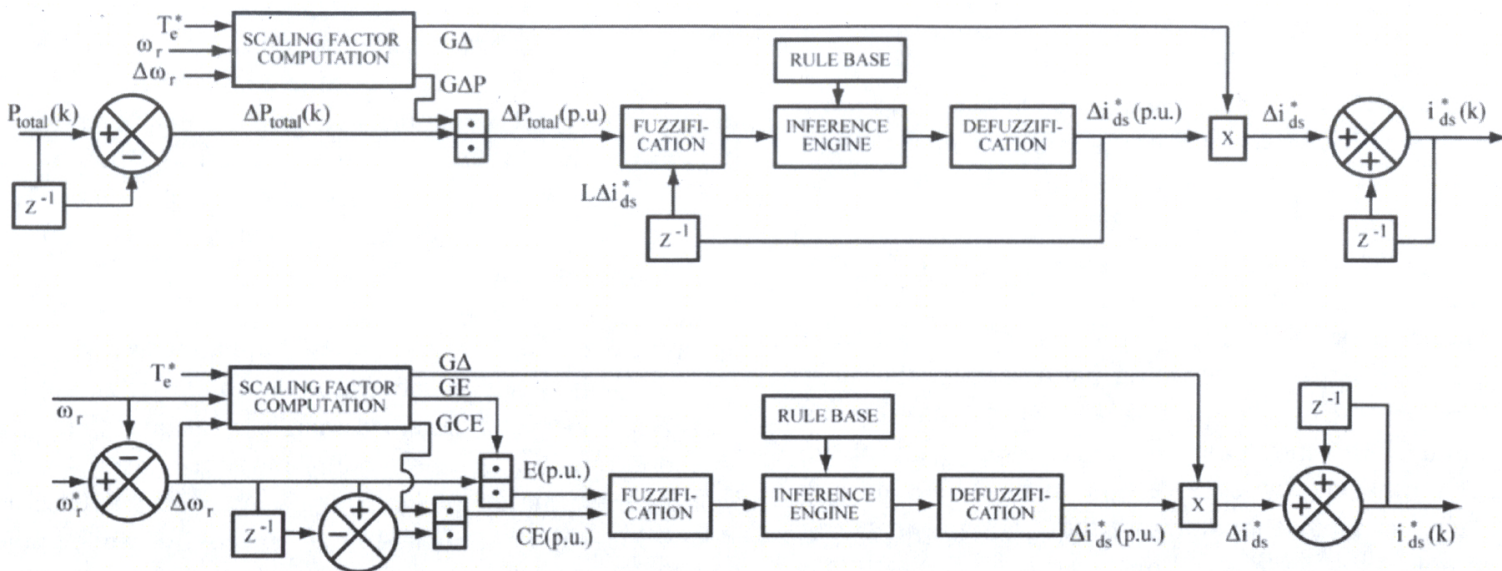

Fig. 1 Top to bottom: Details of the control block diagram of the Fuzzy(1)and Fuzzy(2) controllers.

In Fig.2, the small symmetrical overlap of the positive (P) and negative $(\mathrm{N})$ membership functions is required to prevent indeterminate result in case $\mathrm{L} \Delta \mathrm{i}_{\mathrm{ds}}$ approaches zero. The selected placement of the triagles' peaks and bases provides finer partitioning of the discourse of universe of the small to medium regions, where the sensitivity of the output control variable $i_{d s}(k)$ to input is greater . Each triangle's base length is determined by trial and error iterations in order to fine tune the $F L C$ 's performance and to provide satisfactory control sensitivity and response. Due to the use of input and output gains, all variables are normalized in the universe of discourse $[-1,1]$. Triangular membership functions are chosen to represent the linguistic variables.
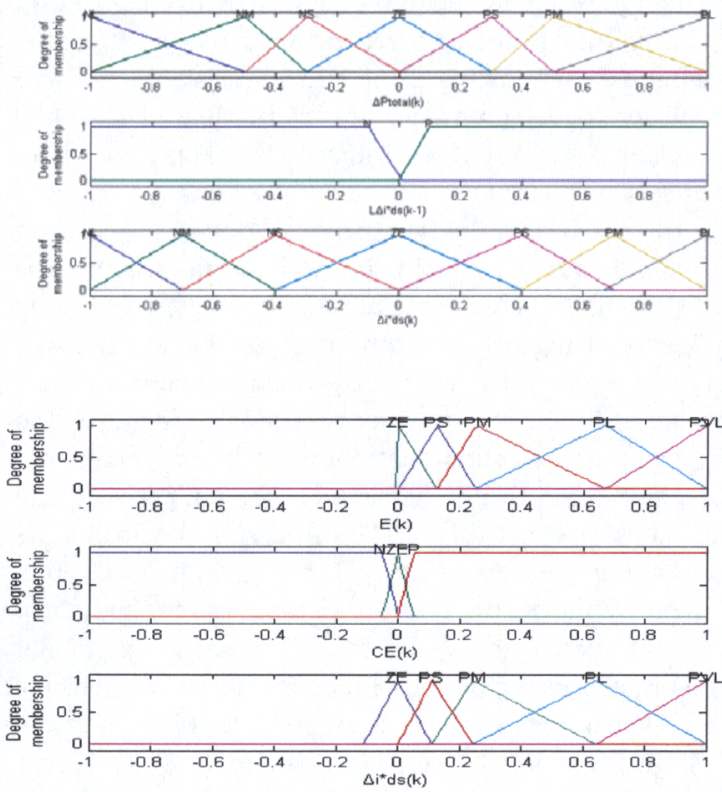

Fig. 2: Top to bottom: The membership functions of the Fuzzy(1), Fuzzy(2) controllers.
The MAX-MIN inference operators are used. The output membership function of each rule is given by the min operator. The combined fuzzy output is given by the MAX operator. The defuzzification is based on the centre of gravity (centroid) method.

For the Fuzzy(1) controller the first fuzzy state variable is the sign and step of power losses decrement $\Delta \mathbf{P}_{\text {total }}(\mathbf{k})$. The second fuzzy state variable is the control action $\mathrm{L} \Delta \mathrm{i}^{*}{ }_{\mathrm{ds}}(\mathrm{k}-1)$ of the previous step. The control variable is the d-axis stator current component $\mathrm{i}_{\mathrm{ds}}$. The variable $\Delta \mathrm{P}_{\text {total }}(\mathrm{k})$ requires 7 memberships

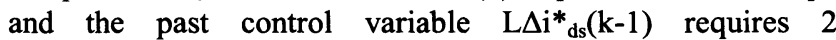
memberships since the main information is the sign. The spectrum of the 7 linguistic variables is defined from positive large (PL) to negative large (NL) and the spectrum of the 2 memberships includes the positive $(\mathrm{P})$ and negative $(\mathrm{N})$. Upon, the sampling of the power losses $P_{\text {total }}(k)$ is compared to the previous value of $P_{\text {total }}(k-1)$ in order to derive the sign and the step change of power losses decrement $\Delta \mathbf{P}_{\text {total }}$. Additionally, the previous action of the magnetizng current decrement $\mathrm{L} \Delta \mathrm{i}_{\mathrm{ds}}(\mathrm{k}-$ $1)$ is reviewed. The new decrement step size $\Delta$ of the $i^{*}{ }_{d s}(k)$ is generated from fuzzy rules through fuzzy inference and defuzzification. The adjustable gains, generated by the scaling factors computation block, convert the state and control variables to per unit (p.u.) values.

Because these gains are speed dependant for different speed and torque conditions, the same $\mathrm{L} \Delta \mathrm{i}^{*}{ }_{\mathrm{ds}}(\mathrm{k}-1)$ (p.u.) will result to different $\Delta \varphi^{*}(\mathrm{k})$ and $\Delta \mathrm{i}^{*}{ }_{\mathrm{ds}}(\mathrm{k})$. If the last control action indicates a decrease of power losses, the $F u z z y(1)$ controller proceeds in searching towards the same direction. In the case of an increase of power losses, the search direction is reversed, and the $\Delta$ step size is reduced to attenuate oscillations in the search process. The steps of the Fuzzy(1)controller are as follows:

1. Sample $\mathbf{P}_{\text {total }}(\mathbf{k})$

2. Compute the decrement $\Delta \mathrm{P}_{\text {total }}(\mathrm{k})$. 
3. Identify the interval index for $\Delta \mathbf{P}_{\text {total }}(k)$ by the comparison method.

4. Compute the degree of membership of the $\Delta \mathbf{P}_{\text {total }}(k)$ and $\mathrm{L} \Delta \mathrm{i}_{\mathrm{ds}}(\mathrm{k}-1)$ for the relevant fuzzy subsets.

5. Identify the valid rules and calculate the degree of membership using the MIN operator.

6. Use the MAX operator to determine the combined fuzzy output.

7. Use the centre of gravity method for defuzzification, so to infer the control increment $\Delta$.

8. Compute the next control signal as $\mathrm{i}_{\mathrm{ds}}(\mathrm{k})=\mathrm{i}_{\mathrm{ds}}(\mathrm{k}-$ 1) $+\mathrm{G} \Delta \mathrm{x} \Delta \mathrm{i}_{\mathrm{ds}}(\mathrm{k}-1)$, where $\mathrm{G} \Delta$ is the gain factor.

The Fuzzy(2) controller fires up during transient state, when the absolute value of speed error is greater than a value depended on the sampling frequency of A/D Converter, in order to get fast response and low overshoot with simultaneous power losses minimization. This transient state is not caused by the fuzzy optimization step adjustments, but is caused due external torque and speed disturbances. Because this controller solely increases the flux, it provides only positive flux increments and its rules are suitable for a positive torque transition and for a positive reference speed change. For the Fuzzy(2) the first fuzzy state variable is the speed error $\mathrm{E}(\mathrm{k})=\omega^{*}{ }_{\mathrm{r}}(\mathrm{k})-\omega_{\mathrm{r}}(\mathrm{k})$, where the $\omega^{*}{ }_{\mathrm{r}}(\mathrm{k})$ is the output signal of the reference model and $\omega_{\mathrm{r}}(\mathrm{k})$ is the process output at time $\mathrm{k}$. The second fuzzy state variable is the change of speed error $\mathrm{CE}(\mathrm{k})$. The $\mathrm{CE}(\mathrm{k})$ is the difference $\mathrm{E}(\mathrm{k})-\mathrm{E}(\mathrm{k}-1)$. The control variable is the flux stator current component $\mathrm{i}_{\mathrm{ds}}$. The universe of discourse for the $E(k)$ fuzzy variable is divided into 5 overlapping memberships: from positive big (PVL) to zero (Z). The state variable $\mathrm{CE}(\mathrm{k})$ requires 3 memberships positive $(\mathrm{P})$, zero $(\mathrm{ZE})$ and negative $(\mathrm{N})$. The underlying principle for the Fuzzy(1) and Fuzzy(2) controllers is the same, except that the variables are different. The methodology of the function of Fuzzy(2) is as follows: If $\mathrm{E}(\mathrm{k})$ decreases, the change of the control signal $\Delta$ depends on the magnitudes and signs of $E(k)$ and $\mathrm{CE}(\mathrm{k})$ signals. If $\mathrm{E}(\mathrm{k})$ and $\mathrm{CE}(\mathrm{k})$ are approaching to zero then maintain present control and set $\Delta($ new $)=0$. The steps of the $F u z z y(2)$ are as follows:

1. Sample $\omega_{\mathrm{r}}{ }_{\mathrm{r}}(\mathrm{k})$ and $\omega_{\mathrm{r}}(\mathrm{k})$.

2. Compute the speed error $E(k)$ and change of $E(k)$.

3. Identify the interval index for $E(k)$ and $\mathrm{CE}(k)$ by the comparison method.

4. Compute the degree of membership of the $E(k)$ and $\mathrm{CE}(\mathrm{k})$ for the relevant fuzzy subsets.

Steps: 5-6-7-8 are the same with Fuzzy(1) controller.

\section{Methodology Of The Proposed EFficienCy System}

Our efficiency fuzzy control system is incorporated into an indirect vector speed controller for a PMSM, as the Fig. 3 shows. The operation sequence can be explained as follows:

Initially, when the motor starts up, it is operated at rated excitation and the rated flux is established. Then the total power losses are calculated by the Power Processing Unit.

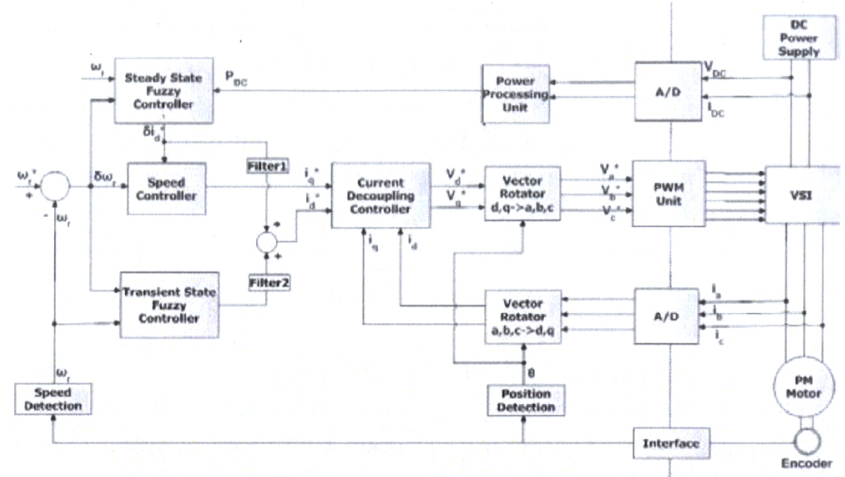

Fig. 3 General block diagram of PMSM drive with indirect vector control, incorporating the proposed fuzzy efficiency system

Then the actual motor speed $\omega_{\mathrm{r}}$ converge is done by comparing the speed error for three consecutive measurements in a time fraction interval of $\tau_{\omega}$. The $\tau_{\omega}$ is determined from the sampling time of the speed signal $T_{s \omega}, \tau_{\omega}=n T_{s \omega}$. The $T_{s \omega}$ varies as a function of the actual PWM pattern. When the speed error between every two consecutive values is less than a small absolute value $e_{\omega}$, (steady state), the search procedure is initiated by the Fuzzy(1) controller. If the absolute value of the speed error is bigger than a certain limit of the speed error $\mathbf{e}_{\omega}$ (i.e. $10 \mathrm{rpm}$ ) the Fuzzy(1) controller will be deactivated and Fuzzy(2) controller will be activated (transient state). Only one fuzzy controller will be active in given moment. During both states (steady and transient) the fuzzy controllers are used to derive the next control action $\Delta \mathrm{i}^{*}{ }_{\mathrm{ds}}(\mathrm{k})$. In steady state the control signal $\Delta \mathrm{i}^{*}{ }_{\mathrm{ds}}$ is generated from the measured change of total power losses $\Delta \mathbf{P}_{\text {Total }}(\mathrm{k})$ and the last control action $\mathrm{L} \Delta \mathrm{i}^{*}{ }_{\mathrm{ds}}(\mathrm{k})$ by the $F L C(1)$. In transient state the control signal $\Delta \mathrm{i}_{\mathrm{ds}}$ is generated from the measured speed error and the change of speed error by the $F L C(2)$. During transient states the objective is to increase at minimum the stator magnetizing current component $\mathrm{i}_{\mathrm{ds}}$, in order to achieve higher torque or speed demand. The vector controller operates sequentially to adjust the torque stator current component $\mathrm{i}_{\mathrm{qs}}{ }_{\mathrm{s}}$ independently in order to achieve the best possible performance, based on the stator flux. Finally, the stator flux is changed, based on the total stator current value.

Because the efficiency optimization is combined with the indirect VC system, it is easy to understand that the innermost current controllers are of the highest priority followed by the speed controller and the fuzzy efficiency controllers. This is implemented using interrupts and timers.

To overcome the problem of torque pulsation, especially for th low-speed operation, a first order low-pass filter is chosen. The filter reaches the $99 \%$ of its reference value after an amount of time which is less than the one needed for the fuzzy controllers to be activated, after the DC link power settles down (corresponding to the change in $i_{\mathrm{ds}}{ }^{*}$ ). In such a case the filter does not influence the speed of the optimization convergence.

As the stator flux does not change instantly, the maximum torque potential following the transition might not be enough to 
overcome a higher torque demand, even with the relaxed current $\mathrm{I}_{\text {limit(1) }}=1.5 \mathrm{I}_{\text {rated. }}$. In such a case, to overcome the

problem of torque stability and to keep it at a safe level (in order to protect the drive to stall during a transition of a steady to a transient state), a current $I_{\text {limit(2) }}$ equal to the rated motor current is imposed.

The torque stator current component is calculated by the feedback speed control loop as indicated by the equation:

$\mathrm{i}_{\mathrm{q}}{ }^{*}=\mathrm{T}_{\mathrm{e}} \mathrm{L}_{\mathrm{q}} / \varphi \mathrm{p} \mathrm{L}_{\mathrm{m}}$

the $T_{e}, L_{q}, L_{m}, \varphi, p$ are defined in nomeclature.

The actual values $\mathrm{i}_{\mathrm{ds}}{ }^{*}$ and $\mathrm{i}_{\mathrm{qs}}{ }^{*}$ are inputs in the decoupling current controller in order to calculate the corresponding feed forward (F-F) voltage commands $v_{d}^{*}$ and $v_{q}^{*}$ by the following equations:

$$
\begin{aligned}
& \mathrm{v}_{\mathrm{d}}{ }^{*}=\mathrm{v}^{*}{ }_{\mathrm{F}-\mathrm{F} \mathrm{d}}+\mathrm{v}_{\mathrm{PI} \mathrm{d}} \\
& \mathrm{V}_{\mathrm{PId}}=\mathbf{R}_{\mathrm{s}}\left(\mathrm{i}_{\mathrm{F}-\mathrm{Fd}}^{*}+\mathrm{v}_{\mathrm{F}-\mathrm{Fd}}^{*} / \mathbf{R}_{\mathrm{c}}\right) \\
& \mathrm{V}^{*}{ }_{\mathrm{F}-\mathrm{F} \mathrm{d}}=-\omega_{\mathrm{r}} \mathrm{L}_{\mathrm{q}} \mathrm{i}_{\mathrm{F}-\mathrm{F} \mathrm{q}}+\mathrm{L}_{\mathrm{d}}\left(d \mathrm{i}_{\mathrm{F}-\mathrm{F} \mathrm{d}}^{*} / d \mathrm{t}\right) \\
& \mathrm{v}_{\mathrm{q}}{ }^{*}=\mathrm{v}_{\mathrm{F}-\mathrm{Fq}}{ }^{*}+\mathrm{v}_{\mathrm{PI}} \mathrm{q} \\
& \mathrm{v}_{\mathrm{PI}}=\mathrm{R}_{\mathrm{s}}\left(\mathrm{i}_{\mathrm{F}-\mathrm{Fq}}^{*}+\mathrm{v}_{\mathrm{F}-\mathrm{F} q}^{*} / \mathrm{R}_{\mathrm{c}}\right) \\
& \mathrm{v}^{*}{ }_{\mathrm{F}-\mathrm{Fq}}=\omega_{\mathrm{r}}\left(\mathrm{L}_{\mathrm{d}} \mathrm{i}_{\mathrm{F}-\mathrm{F} \mathrm{d}}+\varphi\right)+\mathrm{L}_{\mathrm{q}}\left(d_{\mathrm{i}-\mathrm{Fq}}^{*} / d \mathrm{t}\right) \\
& \text { the } R_{s}, R_{c}, L_{q}, L_{d}, \omega_{r}, \varphi \text {, are defined in Nomeclature. }
\end{aligned}
$$

The equations (3)-(8) are based on the synchronous frame $D$ $Q$ model of the PM motor [24]. The $i_{d}$ refers to the fuzzy stator flux current component, $i_{q}$ refers to the stator torque current component, generated by the speed controller. The $v_{d}, v_{q}$ voltages are transformed to the three phase voltage commands $\mathrm{v}_{\mathrm{a}}{ }^{*}, \mathrm{v}_{\mathrm{b}}{ }^{*}, \mathrm{v}_{\mathrm{c}}{ }^{*}$, in the reference stationary frame and are applied to the pulse width modulation (PWM) unit. The PWM unit calculates an asymmetric pulse pattern. To generate the phase voltages with variable amplitude and frequency a 3-phase inverter is used, based on an insulated gate bipolar transistors IGBTs technology. Our proposed system includes a tachogenerator to measure the speed, a resistor divider to sense the voltage bus (VBUS), and a resistor sensor on the line (IBUS) to estimate the phase currents.

\section{SIMULATION RESULTS AND DISCUSSION}

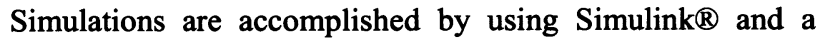
normalized in per unit d-q PMSM dynamic model, including iron losses, as given by [16]. The specifications and the motor parameters for the interior PMSM are listed in table I.

TABLE I

\begin{tabular}{|c|c|c|c|c|}
\hline \multicolumn{5}{|c|}{ Parameter Values In P.U. For Simulation Of An I-PMSM } \\
3 pole pairs, $220 \mathrm{~V}$ three phase $50 \mathrm{~Hz}, 1.5 \mathrm{~kW}, 7 \mathrm{~A} ; 209.3 \mathrm{rad} / \mathrm{s}$ \\
\hline$\varphi$ & $\mathbf{L}_{\mathrm{d}}{ }^{*}$ & $\mathbf{L}_{\mathrm{q}}{ }^{*}$ & $\mathbf{R}_{\mathrm{s}}$ & $\mathbf{R}_{\mathrm{c}}=\mathbf{R}_{\mathrm{co}} \omega_{\mathrm{r}}\left(1+\omega_{\mathrm{r}}\right)$ \\
\hline 0.857 & 0.35 & 0.6 & 0.104 & $\mathbf{R}_{\mathrm{co}}=52$ \\
\hline
\end{tabular}

The simulator is modeled as in Fig. 3, without including the computations for the vector rotator, the PWM and the encoder. The current is sampled every $0.1 \mathrm{~ms}$, the speed is sampled every $1 \mathrm{~ms}$, and the efficiency control system is activated every $0.26 \mathrm{~s}$ (the time interval of $0.26 \mathrm{~s}$ natural considers the slow dynamics of the stator flux, is related with the motor time constant). The input power is calculated by using a sampling period $1 \mathrm{~ms}$, same as the speed loop, and then averaged over 20 $\mathrm{ms}$, by the equation:

$$
P_{\text {in }}=3\left(v_{d s} i_{d s}+v_{q s} i_{q s}\right) / 2
$$

The process of simulation and the efficiency improvement by using the complete proposed efficiency system for the drive is given in Fig. 4. The efficiency control system is activated when the $1^{\text {st }}$ steady state is detected, after the rated flux is established and the motor starts up from zero to rated speed, under 0.3 p.u. constant load torque.

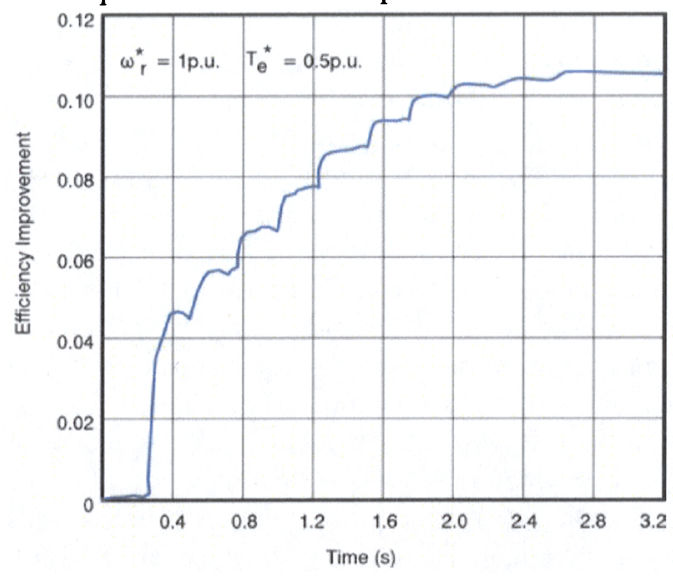

Fig. 4 Simulation results of the response of the drive's efficiency and its improvement. The motor operates at a constant rated speed 1 p.u. under a 0.3 p.u. load torque. In such a case the efficiency optimization, achieved after 10 iterations (of average duration $2.6 \mathrm{~s}$ ), is $10.6 \%$.

Fig. 5 shows the simulation results of the PMSM drive power losses in the case of its control by the proposed fuzzy efficiency system (black line) and in the case of operating the motor at rated flux (red line). When the motor operates under torque load of 0.3 p.u and constant reference speed of 1 p.u., the power losses from $49.3 \pm 4.0 \mathrm{~W}$ are reduced to $30.7 \pm 4.0 \mathrm{~W}$ (minimization rate $37 \%$ ). When a step torque transition occurs from 0.3 to $0.7 \mathrm{p} . \mathrm{u}$, the power losses from $80.1 \pm 6.7 \mathrm{~W}$ are reduced to $79.1 \pm 6.7 \mathrm{~W}$ (minimization rate $1.2 \%$ ). There is no peak of power during transient states.

The green line in the graph of Fig. 6 shows the simulation results which validate the importance of the Fuzzy(2)controller during transient states. The proposed control system is simulated without using the Fuzzy(2)controller. In this case, at the transient point $t=100 \mathrm{~s}$, the power losses increase instantly to $106.5 \mathrm{~W}$, and a speed disturbance occurs (Fig. 7). During the transient state, the calculated consumed energy losses are decreased from $210.6 \mathrm{~J}$ to $168.0 \mathrm{~J}$ (decrease rate $19.9 \%$ ).

Fig. 7 represents the simulation results of the motor's speed response. At the transient point $\mathrm{t}=100 \mathrm{~s}$, the motor's rated speed decreases from $2000 \mathrm{rpm}$ to $1920 \mathrm{rpm}(-0.04 \%)$. At the transient point $t=150 \mathrm{~s}$, the speed value of $2000 \mathrm{rpm}$ increases to $2065 \mathrm{rpm}(+0.032 \%)$. The speed decrease is about three times less than the one that occurs without the use of the 


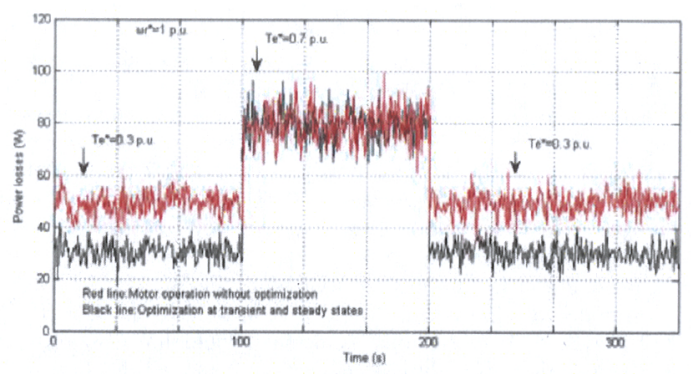

Fig. 5. Simulation results for the case of a step torque load increase of 0.3 to 0.7 p.u., under constant speed, 1 p.u.. Red line: the motor operates at rated flux. Black line: the efficiency is optimized during steady and transient states. The power losses improvement is $37 \%$ and $1.2 \%$ for the cases of torque 0.3 and 0.7 p.u. respectively.

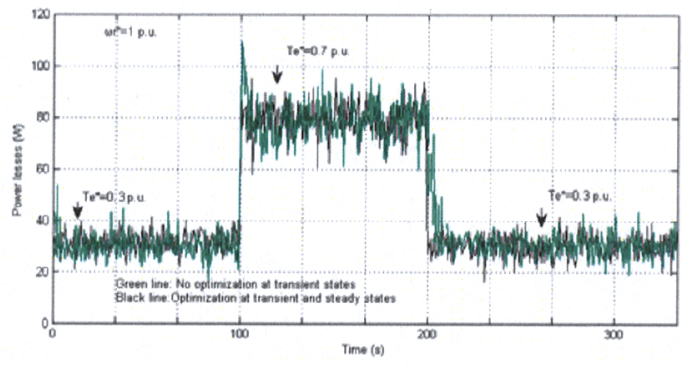

Fig. 6. Simulation results of the proposed efficiency control system as the Fuzzy(2) controller is not activated (green line). The black line indicates the efficiency control during transient and steady states. The torque load increases from 0.3 to 0.7 p.u and the reference speed is 1 p.u. The decrease of energy losses $(\mathrm{J})$ during the torque step transition is $19.9 \%$.

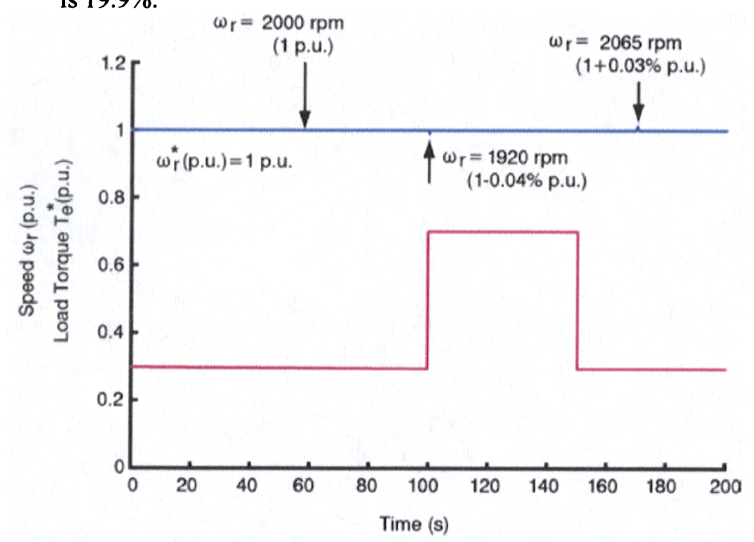

Fig. 7 Simulation results of the motor's speed response when is efficiency controlled by the complete proposed system, for a step torque load increase of 0.3 to 0.7 p.u., under constant reference speed, 1 p.u. fuzzy(2) controller and five times smaller than the one that occurs without optimization control. The calculation time for the fuzzy controllers is $5 \mu \mathrm{s}$, and for the vector control system is less than $0.14 \mathrm{~ms}$.

\section{CONCLUSION}

The proposed method achieves very satisfactory results in the overall losses minimization of a motor drive system as it considers both cases of operation: transient and steady state. The described scheme offers no reduction in the maximum shaft torque, due to the advantages of the fuzzy energy optimizers enabled.

Moreover, the proposed system can be easily incorporated into an existing vector drive system with a minimum of extra hardware implementation and is furthermore independent of the various machine models. Additional software can be executed easily by the included system processor.

The outline of the advantages of the present method are summarized as follows:

(i) The proposed fuzzy efficiency control system accounts for both the PMSM losses and power supply converter losses. That guaranties higher flux level and improves the drive robustness for speed and torque disturbances. Moreover the efficiency improvement is greater for bigger motors where the inverter losses become more significant; The proposed system is independent of drive parameters and can materialized with a minimum of extra hardware, easily incorporated to any size or type of speed drive. The efficiency improvement, for low loads ( 0 to 0.3 p.u.) and rated speed, is about $35 \%$ and for high loads (e.g. 0.7 p.u.) is $1 \%$

(ii) The proposed system achieves very good results of the overall loss minimization of the motor drive system as it takes in account both transient and steady state operation. For many Industrial control applications, transient response of the drives is of extreme importance. The energy losses during transient states are about $20 \%$ for torque disturbances and more than $30 \%$ in the case of speed disturbances.

(iii) The torque stator current component is generated by the vector controller based on the speed demand and the stator flux value, for higher motor performance.

\section{NOMENCLATURE}

* Superscript indicates reference values s subscript indicates the ones in stationary frame $\mathrm{d}, \mathrm{q}$, subscript indicates the d-axis, $\mathrm{q}$-axis components F-F subscript indicates feed -forward value PI subscript indicates value generated by PI controller $G$ capital first letter indicates gain factor $d / d \mathrm{t}$ indicates time derivative

$T_{e}$ is the electromagnetic torque in p.u.

$\mathrm{L}_{\mathrm{q}}$ is the q-axis inductance in p.u.

$\mathrm{L}_{\mathrm{m}}$ is the magnetizing inductance in p.u.

$\varphi$ is the flux produced by the permanent magnets in p.u. 
Proceedings of the 2008 International Conference on Electrical Machines

$\mathrm{p}$ is the number of pole pairs

$R_{s}$ is the equivalent stator copper-loss resistance in p.u

$R_{c}$ is the equivalent stator iron-loss resistance in p.u.

\section{REFERENCES}

[1] P. Pillay, R. Krishnan, "Application characteristics of permanent magnet synchronous and brushless dc motors for servo drives," IEEE Transactions on Industry Applications, Vol. 27, No. 5, pp. 986-996, 1991.

[2] B. K. Bose, "A high-performance inverter-fed drive system of an interior permanent magnet synchronous machine," IEEE Transactions on Industry Applications, Vol. 24, pp. 987-997, 1988

[3] S. Morimoto, Y. Takeda, T. Hirasa, "Current phase control methods for permanent magnet synchronous motors," IEEE Transactions on Power Electronics, Vol. 5, pp. 133-139, 1990.

[4] S. Morimoto, Y. Tong, Y. Takeda, T. Hirasa, "Loss minimization control of permanent magnet synchronous motor drives," IEEE Transactions on Industrial Electronics, Vol. 41, pp. 511-517, 1994.

[5] S. Vaez V. I. John, M. A. Rahman, "An on-line loss minimization controller for interior permanent magnet motor drives," IEEE Transactions on Energy Conversion, vol. 14, pp. 1435-1440, 1999.

[6] C. Mademlis, J. Xypteras, N. Margaris, "Loss minimization in surface permanent-magnet synchronous motor drives," IEEE Transactions on Industrial Electronics, vol. 47, pp. 115-122, 2000.

[7] Y. Nakamura, T. Kudo, F. Ishibashi, and S. Hibino, "High-efficiency drive due to power factor control of a permanent magnet synchronous motor," IEEE Trans. Power Electron., vol. 10, pp. 247-253, Mar. 1995.

[8] D. S. Kirschen, D. W. Novotny, and W. Suwanwissot, "Minimizing induction motor losses by excitation control in variable frequency drives", IEEE Trans. Ind. Appl., vol. IA-20, no. 5, pp. 1244-1250, Sep./Oct. 1984.

[9] E. S. Sergaki, G. S. Stavrakakis "Optimal speed trajectory tracking of an AC motor drive system with simultaneous minimization of its electromagnetic losses and fuzzy logic efficiency optimization in steady and transient states", ICEM 2006, XVII International Conference on Electrical Machines, September 2-5, 2006.

[10] G. D. D. Sousa, B. K Bose, J. G. Cleland, "Fuzzy logic based on-line efficiency optimization control of an indirect vector-controlled induction motor drive," IEEE Transactions on Industrial Electronics, Vol. 42, pp. $192-198,1995$.

[11] T. M. Jahns, G. B. Kliman, and T. W. Neumann, "Interior permanentmagnet synchronous motor for adjustable-speed drives," IEEE Transactions on Industry Applications, Vol. 22, pp. 738-747, 1986.

[12] B. Sneyers, D. W. Novotny, T. A. Lipo, "Field weakening in buried magnet ac motor drives," IEEE Transactions on Industry Applications, Vol. 21, pp. 398-407, 1985.

[13] T. M. Jahns, "Field-weakening regime operation of an interior permanent-magnet synchronous motor drive," IEEE Transactions on Industry Applications, Vol. 23, pp. 681-689, 1987.

[14] S. N. Vukosavic and E. Levi, "Robust DSP-based efficiency optimization of a variable speed induction motor drive," IEEE Trans. Ind. Electron., vol. 50, no. 3, pp. 560-570, Jun. 2003

[15] F. Abrahamsen, J. K. Pedersen, and F. Blaabjerg, "State-of-art of optimal efficiency control of low cost induction motor drives," in Proc. PEMC, Budapest, Hungary, 1996, vol. 2, pp. 163-170.

[16] S. A. Nasar, I. Boldea, and L. E. Unnewehr, Permanent Magnet, Reluctance and Self-Synchronous Motors. Boca Raton, FL: CRC Press, 1993.

[17] S. Morimoto, Y. Takeda, T. Hirasa, and K. Taniguchi, "Expansion of operating limits for permanent magnet motor by current vector control considering inverter capacity," IEEE Trans. Ind. Applicat., vol. 26, pp. 866-871, Sept./Oct. 1990.

[18] B. J. Chalmers, L. Musaka, and D. F. Gosden, "Variable-frequency synchronous motor drives for electric vehicles," IEEE Trans. Ind. Applicat., vol. 32, pp. 896-903, July/Aug. 1996.

[19] E. S. Sergaki, G. S. Stavrakakis, "Optimal speed trajectory tracking of an AC motor drive system with simultaneous minimization of its electromagnetic losses and fuzzy logic efficiency optimization in steady and transient states", XVII International Conference on Electrical Machines (ICEM 2006), Chania, Greece, Sep. 2006.
[20] G. Kim, I. Ha, M. Ko "Control of induction motors for both high dynamic performance and high efficiency," IEEE Transactions on Industrial Electronics, Vol. 39, pp. 323-333, 1992.

[21] V. Sadegh et al, "An on-line loss minimization controller for the Interior Magnet motor drives", IEEE Transactions on Energy Conversion, $p$. 1435-1440, vol. 14, no. 4 Dec. 1999.

[22] M. Cipolla, J.Moreno, "Fuzzy control of an induction motor with compensation of system dead-time", IEEE Power Electronics Specialist Conference, PESC'96, Baveno, Italy, p. 677-681, 24-27 June 1996.

[23] J.Moreno, M.Cipolla, J.Peracaula, "Induction motor drives energy optimization in steady and transient states: A new approach", EPE 97, p. 3.705-3.710, Trodheim, 1997.

[24] B.K. Bose, Power Electronics and AC Drives, Prentice Hall, 1986

[25] F.F. Bernal, A.G. Cerrada, R. Faure, "Model-Based Loss Minimization for DC and AC Vector-Controlled Motors Including Core Saturation", IEEE Transactions on industry Applications, vol. 362, No 3, p. 755-763, May/June 2000. 